\title{
Reactivación económica ecuatoriana: ¿Impacta al sector productivo en el primer semestre del año 2018?
}

\section{Ecuadorian economic reactivation: does it impact the productive sector in the first semester of the year 2018?}

Juan Emilio Balás León

Universidad Politécnica Salesiana

Irma Angélica Aquino Onofre

Universidad Laica Vicente Rocafuerte

Alexander Pavel Cedeño Velasco

Universidad de Guayaquil

Williams Marcelo Basantes Valverde

Consultor Independiente

Autor para correspondencia: jbalas@ups.edu.ec, iaquinoo@ulvr.edu.ec, alexander.cedenove@ug.edu.ec,wmbv@alu.ua.es

Fecha de recepción: 10 de Marzo de 2018 - Fecha de aceptación: 15 de Agosto de 2018

Resumen: Esta contribución trata sobre el impacto que ha tenido la ley de reactivación económica propuesta por el gobierno de Lenin Moreno en las empresas ecuatorianas con corte al primer semestre del año 2018. Se inicia revisando bases teóricas sobre definición de tributos, consecuencias y comportamiento del déficit fiscal, análisis de los rubros del presupuesto general del Estado, incentivos, comportamiento de la inversión nacional - extranjera, dinero electrónico y las últimas reformas tributarias del gobierno anterior. En los aspectos metodológicos se aplica la técnica del panel de expertos para obtener sus criterios y experiencia profesional en la temática planteada, se escogió trabajar con el sector ganadero, bancario, seguros, productivo, transporte y hotelero, los temas a indagar fueron divididos en tres bloques tratando de exoneración del impuesto a la renta, manejo de plusvalía, dinero electrónico, deuda con el Instituto Ecuatoriano de Seguridad Social, refinanciación de deuda externa, tratados bilaterales, crecimiento de la economía, destino del petróleo y reactivación económica. Con las respuestas de los mismos se plantean reflexiones en la discusión y se determinan las conclusiones.

Palabras Claves: reactivación económica 2018; impacto; sector productivo ecuatoriano

Abstract: This contribution deals with the impact that the law of economic reactivation proposed by Lenin Moreno's government has had in Ecuadorian companies with scope to the first semester of the year 2018. It begins checking theory bases on definition of tributes, consequences and behavior of the fiscal deficit, analysis of the headings of the general budget of the State, incentives, and behavior of the national - foreign investment, electronic money and the latest tax reforms of the previous government. In the methodological aspects the panel of experts technique is applied to obtain their criteria and professional experience in the subject matter, it was chosen to work with the livestock, banking, insurance, productive, transport and hotel sectors, the topics to be 
investigated were divided into three blocks trying to exonerate income tax, management of surplus value, electronic money, debt with the Ecuadorian Social Security Institute, refinancing of external debt, bilateral treaties, growth of the economy, oil destination and economic reactivation. With the same responses, reflections are raised in the discussion and the conclusions are determined.

Key words: economic reactivation 2018; impact; ecuadorian productive sector

\section{Introducción}

La Ley de Reactivación Económica propuesta para aplicarse en el territorio ecuatoriano en el año 2018 bajo el mandato del Presidente Lenin Moreno plantea novedades, es así que determina incentivos tributarios para pymes y exportadores. Todo el discurso que se está manejando es para disminuir el déficit fiscal, el mismo que afecta a diferentes ejes de la economía que son la falta de inversión pública, reducción del tamaño del estado, compromisos de pago y crecimiento de la deuda externa.

Reducir el tamaño del déficit del estado no es sencillo, al nivel de deuda que posee el Ecuador, por lo menos necesita ahorrar mil millones de dólares anuales y eliminar aproximadamente a 54 mil funcionarios públicos; lo que equivale a desemplear al $12 \%$ de la población. Muchos policías, médicos y profesores sufrirían este efecto. También se busca la amnistía tributaria para que se recauden ingresos de años anteriores eliminando intereses y otorgando facilidades de pago. La inversión pública es necesaria porque mueve la economía, genera trabajo y dinamiza a los diferentes sectores. Sin embargo, no mejora la evolución del producto interno bruto en el sector productivo no solamente por la caída de los precios de petróleo del 2015 y 2016, también influye en no haber realizado un plan con las medidas necesarias para reactivar la economía.

El sector productivo en el Ecuador está constituido, en un alto porcentaje, por pequeñas empresas que, para desarrollar proyectos de innovación, dependen en gran medida del apoyo de otras organizaciones que proporcionan asesoría, capacitación y/o venta de servicios especializados. Por esta razón, las actividades en el mismo son de gran importancia para las empresas de pequeña y mediana dimensión, puesto que les permiten beneficiarse de capacitación y asesoría integral a sus procesos. (Ecuador R. N., 2018)

El sector productivo está compuesto por diversos agentes que aportan en la recaudación de tributos, en los actuales momentos la inversión extranjera y nacional es mínima producto de los acuerdos y negociaciones pactados en el Gobierno final del Eco. Correa. Esta investigación busca hacer un análisis considerando las opiniones de diferentes personajes de los ejes productivos para determinar cómo los temas económicos, tributarios y de comercio exterior que se han puesto en ejecución inciden en el desarrollo empresarial en el primer semestre del año 2018.

\section{Justificación}

La reactivación económica genera conocimientos y plantea reflexiones sobre las variables económicas impuestas por el Gobierno actual del Lcdo. Moreno para hacer frente a los compromisos de pago heredados y busca la forma en que las diferentes empresas deben aceptar 
dichas medidas planteando las mejoras necesarias para continuar con sus negocios en marcha. Al mismo tiempo, se obtiene puntos de vista de un panel de expertos desde una perspectiva fiscal, comercial y legal en los puntos favorables y adversos que generan repercusión en el comercio nacional e internacional para saber si ayuda o perjudica a la ciudadanía.

\section{Objetivos}

\section{Objetivo General}

Analizar los temas de mayor relevancia en la ley de reactivación económica que generan impacto en el sector productivo ecuatoriano durante el primer semestre del año 2018.

\section{Objetivos Específicos}

- Realizar una revisión en aspectos teóricos sobre los antecedentes relacionados con la reactivación económica en el Ecuador.

- Determinar un panel de expertos pertenecientes a los sectores clave del país para dirigir la temática de la investigación.

- Utilizar técnicas de investigación al panel seleccionado para obtener su punto de vista y criterios relevantes sobre los temas económicos más importantes en el primer semestre del año 2018 para el Ecuador.

\section{Marco teórico}

Primero se debe partir de la naturaleza de impuestos, que se refieren a tributos. La idea de los mismos es cumplir con las obligaciones internas y externas que tiene una nación, en el caso del Ecuador el problema que existe es que está sobre endeudado y se ha tenido un gobierno que está en postura de separación, entonces el ex Presidente Rafael Correa ha hecho cosas acertadas y algunas ineficientes, pero ha dejado una nación que tiene que cumplir con requisitos y compromisos pactados, tenemos una deuda externa lo que implica que todos debemos contribuir a través de nuestros impuestos tanto personas naturales como jurídicas.

Son aquellos tributos que no se definen por medio de una contraprestación inmediata de un servicio o actividad desarrollada por la administración estatal, esta es su característica principal y cumple con el objetivo de financiar los gastos fiscales. Señalamos el hecho de que no es una contraprestación inmediata puesto que los impuestos no hacen alusión a una determinada actividad que realiza el estado pero este devolverá a través del tiempo; los impuestos se ven revertidos en la satisfacción de las necesidades de un colectivo, como por ejemplo la educación fiscal, seguridad pública, etc. (Morales, 2011)

También conocido como tributo, es la carga que los sujetos que viven en determinada sociedad, nación o país deben pagar al Estado, para que el mismo, a través de la recaudación, pueda financiar sus gastos públicos según las prioridades del mismo, es decir, obras públicas que pretendan mejorar la calidad de vida de los sectores más pobres y sin recursos y dinamizar el sector productivo. (Morales Figueroa, 2015) 
El déficit es la carencia de dinero efectivo, causa iliquidez por parte del Estado para poder cumplir con todas las obligaciones en el corto plazo que tenemos, nos lleva a una encrucijada muy fuerte. Debemos tener en cuenta que los impactos para especialmente las clases más bajas son sumamente fuertes de llevar. No es fácil pelear un déficit especialmente cuando está tan avanzado como el que tenemos, y aunque es una utopía decir que se puede eliminar, sí puede haber mecanismos y medidas que se tomen para que siga creciendo.

El déficit cerró en USD 5838 millones; es decir, un incremento del 43\% frente al 2016. Para cubrirlo, el Gobierno buscó financiamiento en el exterior, lo cual incidió en aumento de endeudamiento. Hasta noviembre del 2017, el saldo de la deuda agregada total del país era de USD 46554 millones, mayor al 2016 (USD 38136 millones). El 2017 fue, además, el año en el que el Gobierno emitió el monto más alto de deuda en bonos en el mercado internacional desde el 2014, cuando volvió a los mercados internacionales, luego de haber caído en 'default' o no pago. Entre enero y octubre se emitieron USD 5500 millones en bonos, a tasas de interés entre $8,75 \%$ y $9,6 \%$. Esto se explica por dos factores. El primero es que el Gobierno no cumplió con su meta de recaudación tributaria. Aunque desde junio del 2017 se bajaron los dos puntos del IVA y se eliminaron las salvaguardias a las importaciones, el Fisco se planteó una ambiciosa meta de USD 14780 millones por tributos. Al cierre del año recaudó 802 millones menos. El segundo factor fue elevación del gasto, pese a las políticas de austeridad. (Comercio, 2018)

Esta situación se crea cuando hay un exceso del gasto público y no se tienen los ingresos necesarios para poder tener un punto de equilibro y economía sana, hoy en día Ecuador se encuentra en un momento complicado, ya que no tiene un ingreso fijo, conocemos que nuestra principal fuente de ingreso es el petróleo y no nos beneficiamos de esto, existe un alto gasto público, generando así lo que llamamos déficit fiscal. A continuación se detalla los rubros del presupuesto general del Estado años 2017 y 2018.

\begin{tabular}{|c|c|c|c|}
\hline & 2017 & 2018 & $\%$ \\
\hline Ingresos totales & $23.546 ' 59$ & $24.864^{\prime} 67$ & 5,6 \\
\hline Ingresos permanentes & $20.272 \times 22$ & $21.552^{\prime} 48$ & 6,3 \\
\hline Ingresos impuestos & $14.760 \cdot 35$ & $15.343^{\prime} 93$ & 4,0 \\
\hline Tasas y contribuciones & $1.6099^{\prime} 81$ & $2.040 ' 25$ & 26,7 \\
\hline Ingresos no permanentes & $3.274: 37$ & $3.312 ' 19$ & 1,2 \\
\hline Gastos totales & $28.341 \cdot 3$ & $28.967 \cdot 48$ & 2,2 \\
\hline Gastos permanentes & $19.175 ' 37$ & $20.924 \cdot 79$ & 9,1 \\
\hline Personal & $9.192 ' 54$ & $9.538^{\prime} 77$ & 3,8 \\
\hline Gastos no permanentes & $9.165 ' 93$ & $8.042 \cdot 68$ & $-12,3$ \\
\hline RESULTADO TOTAL & -4.79471 & -4.10281 & $-14,4$ \\
\hline Financiamiento público & $11.670 ' 33$ & $8.253^{\prime} 75$ & $-29,3$ \\
\hline Saldos disponibles & $610 ' 2$ & $427 \cdot 11$ & $-30,0$ \\
\hline Cuentas por cobrar & $564^{\prime} 93$ & $600^{\circ}$ & 6,2 \\
\hline Ventas anticipadas & $400^{\circ}$ & $695^{\prime}$ & 73,8 \\
\hline Necesidad de financiamiento & $13.245^{\prime} 46$ & $9.975^{\prime} 86$ & $-24,7$ \\
\hline
\end{tabular}

Figura 1: Ministerio de Finanzas del Ecuador, 2017 Fuente: Diario El Universo

La salida para el Gobierno de Lenín Moreno en su afán de que haya equilibrio fiscal y menor endeudamiento tiene varias aristas: reducir el tamaño del Estado, optimizar el presupuesto, la Ley de Fomento Productivo que incluye remisión tributaria para lograr una 
inyección económica en tres años de $\$ 774$ millones o aumentar el precio a ciertos combustibles. Este último punto, para organizaciones como el Frente Popular, no es una opción. Han realizado marchas locales de rechazo y habrá el 20 de septiembre una movilización nacional. (Universo, 2019)

Los incentivos que propone la Ley de Reactivación Económica son pocos, realmente como exportadores no somos tecnificados, los productos fuertes de nuestro país para poder vender son: vegetales, frutas, hortalizas, camarones, orquídeas; productos que no se encuentran fácilmente, es importante que contribuyan a la balanza comercial positiva, pero no fundamentada en que las exportaciones sean mayores que las importaciones sino por la razón de que las exportaciones tienen muchas limitaciones, por ende las preferencias cambian.

Los incentivos tributarios son instrumentos que buscan estimular o impulsar determinados tipos de inversión relacionada con aspectos sociales para una empresa, ya sea pública o privada, manejar los diferentes tipos de incentivos tributarios que pueden aplicar a su actividad económica, siempre resulta de gran utilidad, pues de los mismos deriva la exoneración o disminución de los impuestos, la canalización del ahorro y la optimización de los beneficios. De manera general a través de los años, los gobiernos han procurado de alguna manera ordenar el marco institucional donde operan los agentes económicos privados, con el fin de corregir y superar imperfecciones del mercado. Precisamente reglamentar incentivos tributarios ha sido una de esas medidas, que busca: dar soluciones a la falta de inversión de riesgos en la economía, generar empleos estables de calidad, priorizar la producción nacional y determinados consumos, la contención de precios finales, el desarrollo de regiones atrasadas, la promoción de exportaciones, la industrialización, el cuidado del medio ambiente, la transferencia de tecnología, la diversificación de la estructura económica, la formación de capital humano, entre otros aspectos positivos. (Ocles, 2017)

La reactivación económica piensa aumentar la inversión eliminando el impuesto a la renta, otorgando amnistía tributaria y descartando el impuesto a la salida de divisas. El actual proyecto establece dos porcentajes para la condonación de los recargos. El primero es la remisión del 100\% de los intereses, multas y otros rubros que se hayan generado, siempre que se pague el total del impuesto adeudado dentro de los 60 días hábiles después de la publicación de esta nueva normativa en el Registro Oficial. El segundo porcentaje de condonación corresponde a la exoneración del 50\% de los recargos a partir del día 61 hasta el 90 desde la promulgación de esta nueva ley, siendo necesario destacar que la condonación corresponderá de manera exclusiva sobre intereses y multas, no transgrediéndose el capital de la obligación tributaria generada. (Ab. Jimmy Salazar Gaspar, 2015)

El problema que siempre ha tenido el Ecuador es la inversión; ya que no tiene fondos para comprar maquinarias que se necesita para la producción, dándole valor agregado al producto, un ejemplo muy claro es el cacao ecuatoriano es uno de los mejores del mundo; nosotros lo exportamos a Suiza en donde se hace el mejor chocolate del mundo, cuando nosotros estamos en capacidad de hacer ese mismo chocolate, porque es con nuestro cacao que los suizos lo hacen, pero ellos le dan un valor agregado y si nosotros exportamos 1 kilo de cacao a 1 dólar, ellos nos traen 1 kilo de chocolate y nos venden a 10 dólares, entonces ese es el valor agregado que se le da a este producto que nosotros no lo damos. No obstante, con tantos impuestos y leyes, 
no se atrae a los inversionistas. Nuestro país necesita inversión para cambiar el modelo productivo y desarrollar una verdadera matriz productiva. Tenemos que buscar emprendimiento, pero los que realmente tienen la capacidad de invertir y seguir desarrollando y aportando son los más grandes entonces tenemos que buscar una equidad.

Como por ejemplo, los exportadores ya podían recibir devoluciones, pero lo que sucede es que hay ciertos productos que pueden tener muy buena capacidad de aumento en las exportaciones como el camarón el cual se vuelve a encontrar en un fuerte auge, pero esto de nada va a servir si es que no se efectúan convenios internacionales apropiados. Emprender en Ecuador es un tema complicado que no solo se debe a temas tributarios también tenemos problemas laborales y comerciales. Suiza siendo un estándar de vida per cápita bastante elevado, casi podemos decir que todo suizo es millonario. Ecuador podría ser mucho más con todos los recursos naturales que tiene.

\begin{tabular}{|lrr|}
\hline PIB Trim Per Capita [+] & N Trim 2017 & $17.238 €$ \\
\hline PIB anual $[+]$ & 2017 & $601.016 \mathrm{M} . €$ \\
\hline PIB Per Capita $[+]$ & 2017 & $71.380 €$ \\
\hline PIB Trimestral [+] & N Trim 2017 & $145.148 \mathrm{M} . €$ \\
\hline Deuda total (M.€) [+] & 2016 & 261.919 \\
\hline Deuda (\%PIB) [+] & 2016 & $43,34 \%$ \\
\hline Deuda Per Cápita [+] & 2016 & $31.108 €$ \\
\hline Déficit (M.€) [+] & 2016 & 2.013 \\
\hline Déficit $(\% P I B)[+]$ & 2016 & $0,30 \%$ \\
\hline G. Público $(M . €)[+]$ & 2016 & $207.487,9$ \\
\hline
\end{tabular}

Figura 2: Cuentas Nacionales de Suiza

Fuente: Diario El Comercio

El documento aclara que la reducción se debió a una mejor recaudación tributaria, a la reducción del gasto público y los ingresos del sector petrolero. Entre enero y julio de este año los ingresos por recaudaciones del Impuesto al Valor Agregado (IVA), se incrementaron un doce por ciento, al pasar de 3.283 millones a 3.663 millones de dólares recaudados. Los ingresos petroleros durante el mismo período se ubicaron en 1.300 millones de dólares, el equivalente al 42 por ciento, en relación a los ingresos obtenidos el año pasado, subraya el texto. De acuerdo con el informe, la programación fiscal del Ministerio indica que el déficit global se ubicará en 4,3 por ciento del PIB y el déficit primario en 2,1 por ciento del producto en 2018. La cartera de Estado prevé medidas para los últimos meses del año como el control de los contratos de servicios ocasionales en el sector público y la aplicación de un plan para generar ahorros con mayor transparencia y eficiencia en los procesos de adquisición de bienes y servicios. (República, 2018)

Por otro lado, el gobierno ecuatoriano busca con el dinero electrónico tener más credibilidad financiera, es importante recordar que no tiene respaldo. El Ecuador no está listo aún; en primer lugar porque no tenemos moneda propia y no hay respaldo del Bono del tesoro de los Estados Unidos.

Los bonos del Tesoro de largo plazo se refieren a todos los tipos de títulos de deuda emitidos por el Tesoro de Estados Unidos. A menudo estos se comparan con los productos de 
ahorro bancarios como cuentas del mercado monetario y certificados de depósitos (CD). Los inversionistas los compran cuando quieren evitar los tipos de inversión con mayores niveles de riesgo y con posibilidades de pérdida. Se ofrecen en varios tipos y en una amplia gama de vencimientos. Los billetes del Tesoro son instrumentos de corto plazo con vencimientos de cuatro a 52 semanas. Estos se venden con un descuento y el interés se gana cuando se recibe el valor nominal al vencimiento. Todos los tipos de bonos del Tesoro están respaldados por el poder fiscal del gobierno de Estados Unidos. Estos bonos son considerados la inversión más segura en el mercado. (Plaehn, 2018)

Cuando el dinero electrónico forme parte de la banca privada se buscará una manera de maximizar los beneficios y sobre todo habrá campañas mucho más agresivas para que las personas tomen mayor consciencia de la posible aplicación y de sus usos, cuando se maneja como parte de un estado se lo toma más como una imposición o como una ordenanza a que las personas cambien su estado habitual de vida y eso no sea bien recibido especialmente cuando el gobierno anterior ya no tenía un índice de popularidad tan alto cuando estaba saliendo entonces habían muchas personas que trataban de ver con vista muy reactivos a la mayoría de propuestas de gobierno y el dinero electrónico fue una de las más rechazadas, la banca privada en cambio tiene mecanismos para incentivar a las personas a que traten de ser inclusivos con esta nueva medida siempre y cuando haya un marco regulatorio fuerte.

Es claro que la política económica se robustece a partir de la modernización de la gestión del sistema financiero. Fomentar que las transacciones que se, realizan en la economía pasen por medios de pago electrónicos y el sistema financiero del país, lleva a un mayor nivel de formalidad en la economía, permite mayor transparencia y fomenta la eficiencia del país. Se hace así mismo necesario fortalecer los procedimientos que garantice a la culminación en los procesos de liquidación de entidades financieras, sobre todo las de la Economía Popular y Solidaria, así como facilitar los procesos de fusiones que permitan fortalecer al sector para convertirse en uno de las principales fuentes de financiamiento de los sectores tradicionalmente marginados. (Ecuador A. N., 2017)

En el aspecto tributario la ley de reactivación económica ha generado planteamientos significativos, destacándose la tarifa de impuesto a la renta de sociedades con un incremento del $22 \%$ al 25\%; alza del $25 \%$ al $28 \%$ para sociedades que incluyan accionistas o socios residentes de paraísos fiscales, también aspira eliminar el beneficio de la reducción por reinversión de utilidades.

Se establece la extinción de obligaciones de recuperación onerosa, que sumadas por contribuyente sean de hasta 1 SBU, siempre y cuando a la fecha de emisión de la resolución de extinción, se hayan cumplido los plazos de prescripción de la acción de cobro, se manifiesta que las normas de determinación presuntiva pueden ser aplicables en las liquidaciones de pago por diferencias, se suspende el proceso de ejecución de la deuda cuando se haya concedido facilidad de pago, y no únicamente con la solicitud. (SRI, 2017)

Al mismo tiempo hace mención de la no deducibilidad de provisiones por jubilación y desahucio y cambios al cálculo del anticipo de impuesto a la renta. El borrador del proyecto deseaba captar mayor recaudación fiscal dirigiéndose a la obligación de llevar contabilidad para 
personas naturales con ingresos anuales mayores a US \$300.000; en cuanto al sector familiar los gastos personales estaban limitados en función de la cantidad de cargas familiares. Para las empresas se indica que los dueños respondan de forma solidaria en relación a sus derechos representativos.

Haciendo una reseña del Gobierno del Economista Correa han existido cinco reformas: La primera fue en el 2007, con la Ley de Equidad Tributaria, en la que se estableció el incremento al Impuesto de los Consumos Especiales (ICE) en productos como los cigarrillos (200\%), bebidas y gaseosas (hasta el $20 \%$ más), perfumes (35\%) y automóviles (entre $10 \%$ y el $30 \%$ adicional); además, se creó el Impuesto a la Salida de Capitales (ISC) con una tasa del 0,5\%, se fijó un impuesto a la herencia, y se incrementó el impuesto a la renta máximo de las personas, hasta el 35\%. En el 2008 se fijó en 1\% el ISC y se estableció la reducción del Impuesto a la Renta a las empresas que reinviertan utilidades. La tercera del 2009, impuso el impuesto mínimo o anticipo al IR y el nuevo incremento al ISC, del 1\% al 2\%. La del 2010 modificó la manera de deducir los gastos personales para las personas naturales. Vía reglamento se limitó el monto de deducción de vivienda, vestimenta, alimentación y educación, cambios que deberán aplicarse en el ejercicio fiscal 2011. La quinta se encuentra establecida al final del Código objeto de estudio. (Vera \& Carpio, 2011)

Tomando en cuenta los parámetros señalados anteriormente, se aplicará la metodología para conocer los efectos que cada una de estas medidas afectará o beneficiará a los sectores productivos durante el primer semestre del año 2018.

\section{Metodología}

Se aplicará el instrumento de investigación denominado entrevista enfocado a un panel de expertos que pueden aportan con información y pertenecen a sectores clave de la ciudadanía ecuatoriana económicamente activa.

El panel emite un juicio de valor sobre un programa determinado. El juicio de valor se construye a partir del análisis de la información sobre el programa en base al método del marco lógico. La información del programa deviene de documentación de la institución encargada del programa, como asimismo de evaluaciones diversas que se han hecho sobre él. La opinión se vierte en un formulario creado ex-profeso. Este formulario ha sido estructurado como una ficha de evaluación, en la cual se vacía la información procesada en la construcción del marco lógico del programa. (Vega Morales, 2007)

La entrevista es un elemento de investigación de carácter cualitativa que permite establecer una comunicación entre varias personas, en donde se obtiene a través de la indagación experiencias y datos relevantes que son significativos para la investigación. Se ha escogido a un experto del sector hotelero, transporte, producción, seguros, bancario y del ganadero.

También es el interrogatorio por parte del encuestado preguntándole las preguntas desarrolladas en el cuestionario referentes al interés educativo metodológico con el fin de obtener respuestas sinceras y llenas de contenido. (Azanza Panta, 2014) 
Para conocer los temas económicos de mayor importancia en el primer semestre del año 2018, se ha dividido en 3 bloques de indagación, el primero se relaciona con la exoneración del impuesto a la renta, plusvalía y dinero electrónico. El segundo bloque trata sobre la deuda con el Instituto Ecuatoriano de Seguridad Social, refinanciación de deuda externa y tratados bilaterales. El último bloque se refiere a crecimiento de la economía, petróleo y reactivación económica.

\section{Resultados}

Tabla 1. Experiencia del Panel de expertos enfocado a Exoneración del Impuesto a la Renta, uso del dinero electrónico y eliminación de Ley de Plusvalía

\begin{tabular}{|c|c|c|c|}
\hline Experto & $\begin{array}{c}\text { Exoneración del } \\
\text { Impuesto a la Renta }\end{array}$ & Uso del dinero electrónico & $\begin{array}{c}\text { Eliminación de Ley de } \\
\text { Plusvalía }\end{array}$ \\
\hline $\begin{array}{c}\text { Sector } \\
\text { Hotelero }\end{array}$ & $\begin{array}{l}\text { Ayuda a las microempresas } \\
\text { a que no tendrían que pagar } \\
\text { tanto al estado y podrían } \\
\text { rendir su dinero en la misma } \\
\text { empresa, siendo un } \\
\text { beneficio, pero sería } \\
\text { negativo para el Estado } \\
\text { porque no recaudaría tanto } \\
\text { dinero por este impuesto } \\
\text { que es uno de los que } \\
\text { mayormente subsidia todos } \\
\text { los gastos del estado. }\end{array}$ & $\begin{array}{l}\text { Se utiliza para tarjetas de } \\
\text { débito, crédito, lo que } \\
\text { conlleva a que el Banco } \\
\text { Central preste su nombre en } \\
\text { el mismo por ser un dinero } \\
\text { ficticio en lo que } \\
\text { corresponde a la compra y } \\
\text { venta, deberá tener un } \\
\text { soporte, cuando la otra parte } \\
\text { quiera dinero físico este } \\
\text { hecho provoca } \\
\text { desestabilización económica. }\end{array}$ & $\begin{array}{l}\text { Es una ley que trata de frenar } \\
\text { la especulación en tierra de } \\
\text { personas que tienen } \\
\text { información privilegiada } \\
\text { realizando transacciones que } \\
\text { no son muy éticas yu que les } \\
\text { permite ganar mucho dinero } \\
\text { a costa de muchas veces } \\
\text { duberi que debería financiar } \\
\text { obras públicas. }\end{array}$ \\
\hline $\begin{array}{c}\text { Sector } \\
\text { Transporte }\end{array}$ & $\begin{array}{l}\text { Tenemos que ver el pro y } \\
\text { el contra, por qué si no } \\
\text { tenemos lo que son los } \\
\text { ingresos al estado por los } \\
\text { impuestos a la renta no } \\
\text { habrá más obras, no } \\
\text { tendría instituciones } \\
\text { educativas, carreteras, } \\
\text { edificios, etc. El estado en } \\
\text { realidad que estuviera } \\
\text { tomando una medida } \\
\text { bastante grave al bajar lo } \\
\text { que es el impuesto a la } \\
\text { renta para que la } \\
\text { microempresa pueda coger } \\
\text { y surgir }\end{array}$ & $\begin{array}{l}\text { El dinero electrónico es el } \\
\text { manejo del día, tenemos un } \\
\text { dólar devaluado, lo que se } \\
\text { compra aquí con un dólar } \\
\text { no se puede comprar en los } \\
\text { Estados Unidos, creo que } \\
\text { toda la polémica que se } \\
\text { armó obedece a que los } \\
\text { negocios ejecutan } \\
\text { finalmente pagos } \\
\text { electrónicos donde se } \\
\text { mueve dinero y se } \\
\text { comisiona por eso. }\end{array}$ & $\begin{array}{l}\text { La ley buscaba un buen fin, } \\
\text { al momento de redactarla } \\
\text { no fue rígida respecto a lo } \\
\text { que es una operación } \\
\text { normal de bienes } \\
\text { inmuebles, el monto o } \\
\text { porcentaje que se está } \\
\text { fijando como tributable } \\
\text { para la ganancia } \\
\text { extraordinaria es exagerado } \\
\text { y ha provocado una } \\
\text { recesión completa en el } \\
\text { sector de la construcción, } \\
\text { pues al dejar de ser un } \\
\text { sector atractivo tiene una } \\
\text { afectación muy fuerte para } \\
\text { todos. }\end{array}$ \\
\hline
\end{tabular}




\begin{tabular}{|c|c|c|c|}
\hline $\begin{array}{c}\text { Sector } \\
\text { Seguros }\end{array}$ & $\begin{array}{l}\text { No es mucho el ingreso de } \\
\text { recaudación por este rubro } \\
\text { en microempresa-estado, } \\
\text { los ingresos por renta no } \\
\text { son tan grande como si } \\
\text { fuera una multinacional, } \\
\text { no sería tanto el impacto y } \\
\text { si fuera favorable para que } \\
\text { las empresas tuvieran más } \\
\text { ingresos poder producir } \\
\text { mejor, contratar más } \\
\text { empleados y realizar } \\
\text { bastante inversión } \\
\text { extranjera para tener } \\
\text { mayor capacidad de } \\
\text { empresas, mayor } \\
\text { capacidad de empleo, bajar } \\
\text { la tasa de desempleo. }\end{array}$ & $\begin{array}{c}\text { Para que los bancos } \\
\text { privados comiencen a emitir } \\
\text { cuenta de dinero } \\
\text { electrónico, a los } \\
\text { ciudadanos se debe } \\
\text { incentivar a usar este } \\
\text { sistema, porque tendrá un } \\
\text { aval para que no exista } \\
\text { algún fraude, no como el } \\
\text { banco central que es } \\
\text { manejado por el estado. }\end{array}$ & $\begin{array}{l}\text { Al momento el presupuesto } \\
\text { no se alimenta en gran } \\
\text { medida con los valores que } \\
\text { se recogen de este impuesto } \\
\text { pues ha funcionado durante } \\
\text { muy poco plazo así que } \\
\text { hacer una derogatoria o } \\
\text { cambiar reduciendo el } \\
\text { porcentaje de la ganancia } \\
\text { extraordinaria que es } \\
\text { tributable no va a golpear al } \\
\text { presupuesto del estado, si de } \\
\text { pronto fuese una ley que es } \\
\text { un rubro importante que } \\
\text { financia a la obra del país. }\end{array}$ \\
\hline $\begin{array}{c}\text { Sector de } \\
\text { la } \\
\text { Producción }\end{array}$ & $\begin{array}{l}\text { Con esta disposición las } \\
\text { microempresas puedan } \\
\text { tener dinero para reinvertir } \\
\text { y poder agrandarse, } \\
\text { produciendo más, esto } \\
\text { conlleva a que contraten } \\
\text { personas; pero si esta } \\
\text { medida se van a tomar el } \\
\text { Impuesto a la renta va a } \\
\text { bajar para todas las } \\
\text { personas siendo negativo; } \\
\text { reduciendo las } \\
\text { infraestructuras de obras, } \\
\text { inversiones en carreteras, } \\
\text { etc. }\end{array}$ & $\begin{array}{c}\text { Se perdió la confianza } \\
\text { sobre todo por lo que hizo } \\
\text { el gobierno anterior en las } \\
\text { instituciones del estado y } \\
\text { eso ha creado un estigma, } \\
\text { en definitiva, a nadie le } \\
\text { gusta que el estado maneje } \\
\text { su dinero, el estado a nivel } \\
\text { mundial no es buen } \\
\text { administrador }\end{array}$ & $\begin{array}{c}\text { Esta ley o impuesto } \\
\text { exagerado que se cobra en } \\
\text { ganancia extraordinaria } \\
\text { pueda llegar a un índice } \\
\text { con un nivel un poco más } \\
\text { razonable, sin embargo } \\
\text { debemos ser muy } \\
\text { conscientes de algo, si la } \\
\text { ley actual se deroga no } \\
\text { indica cuál será la nueva } \\
\text { manera de calcular este } \\
\text { impuesto. }\end{array}$ \\
\hline $\begin{array}{c}\text { Sector } \\
\text { Bancario }\end{array}$ & $\begin{array}{c}\text { La eliminación del } \\
\text { impuesto a la renta es para } \\
\text { empresas que facturan } \\
\text { hasta } \$ 300.000,00 \text { dólares } \\
\text { al año entonces en realidad } \\
\text { si ustedes lo dividen al } \\
\text { mensual son facturaciones } \\
\text { pequeñas para empresas } \\
\text { entiéndase que como dice } \\
\text { el Presidente Moreno es la } \\
\text { gran mayoría, en unidad } \\
\text { de empresas la minoría es } \\
\text { la que hace la gran } \\
\text { mayoría de la facturación } \\
\text { y de donde salen pues } \\
\text { justamente los que pagan } \\
\text { los impuestos o el } \\
\text { impuesto a la renta y en } \\
\text { ese caso a ellos se les } \\
\text { subió el 1\%. }\end{array}$ & $\begin{array}{c}\text { Es una propuesta que } \\
\text { definitivamente entrega un } \\
\text { beneficio, ahora el dinero } \\
\text { electrónico es muy } \\
\text { importante y sería muy } \\
\text { bueno que rápidamente la } \\
\text { gente se acostumbre a eso, } \\
\text { el dólar no es nuestra } \\
\text { moneda y no hay mucho } \\
\text { circulante esto obedece a } \\
\text { muchas razones más de } \\
\text { ente económico. }\end{array}$ & $\begin{array}{l}\text { No nos afecta porque no } \\
\text { formamos parte de la gente } \\
\text { con mucho dinero para } \\
\text { comprar tierras en los } \\
\text { sectores estratégicos, por } \\
\text { ejemplo La ciudadela La } \\
\text { Joya, perteneciente al } \\
\text { cantón Daule eran tierras } \\
\text { agrícolas y selva hasta que } \\
\text { alguien la compró, el } \\
\text { municipio de Daule hizo las } \\
\text { carreteras; una hectárea } \\
\text { inicialmente la venden a } \\
\$ 2000, \text { de ésta sacan } 60 \\
\text { casas de un terreno de } 8 \times 16 \\
\text { y esta es revendida a } \\
\$ 70000 \text { u } \$ 80000 \text {. }\end{array}$ \\
\hline
\end{tabular}




\begin{tabular}{|c|c|c|c|}
\hline $\begin{array}{c}\text { Sector } \\
\text { Ganadero }\end{array}$ & $\begin{array}{l}\text { Como empresarios no es } \\
\text { algo que termine de gustar } \\
\text { porque esperábamos algo } \\
\text { distinto en ese tema } \\
\text { puntual, sin embargo } \\
\text { debemos ser solidarios } \\
\text { porque la época actual así } \\
\text { nos lo exige. Los que } \\
\text { tenemos una facturación } \\
\text { mayor a eso que somos tal } \\
\text { vez minoría pero en } \\
\text { dólares somos los que } \\
\text { realmente ayudamos a los } \\
\text { ingresos impositivos y } \\
\text { tributarios }\end{array}$ & $\begin{array}{l}\text { Tiene que tener un respaldo } \\
\text { lógico e inteligente, su } \\
\text { aplicación es conveniente } \\
\text { por seguridad, cuando se } \\
\text { viaja a países de primer } \\
\text { mundo muy poco dinero } \\
\text { efectivo lleva la gente, se } \\
\text { paga con tarjeta de crédito o } \\
\text { débito o con el celular. Las } \\
\text { grandes potencias manejan } \\
\text { el dinero electrónico, en } \\
\text { realidad es un sondeo para } \\
\text { ver cómo se reducen costos } \\
\text { porque la emisión del papel } \\
\text { cuesta. }\end{array}$ & $\begin{array}{l}\text { Actualmente se encuentra } \\
\text { un poco frenado este sector } \\
\text { de la industria, podemos ver } \\
\text { que se están vendiendo } \\
\text { casas y esto frena un poco la } \\
\text { construcción de nuevas } \\
\text { viviendas, existe } \\
\text { desinformación, hay } \\
\text { personas que se dedicaban a } \\
\text { la venta en varias ocasiones } \\
\text { de estos bienes, entonces } \\
\text { como estas personas no } \\
\text { están invirtiendo porque } \\
\text { saben que van a tener una } \\
\text { pérdida al tener que pagar } \\
\text { este impuesto se ha visto } \\
\text { detenido la construcción y } \\
\text { este sector se encuentra } \\
\text { afectado. }\end{array}$ \\
\hline
\end{tabular}

Tabla 2. Experiencia del Panel de expertos enfocado a deuda con el Instituto Ecuatoriano de Seguridad Social, Refinanciación y Tratados Bilaterales

\begin{tabular}{|c|c|c|c|}
\hline Experto & $\begin{array}{l}\text { Deuda con el Instituto } \\
\text { Ecuatoriano de Seguridad } \\
\text { Social }\end{array}$ & $\begin{array}{l}\text { Refinanciación de la Deuda } \\
\text { Externa }\end{array}$ & Tratados Bilaterales \\
\hline $\begin{array}{l}\text { Sector } \\
\text { Hotelero }\end{array}$ & $\begin{array}{l}\text { El IESS como sabemos ha } \\
\text { sido una caja de dinero } \\
\text { flotante, circulante y } \\
\text { permanentemente que se va } \\
\text { llenando, no le hacen falta } \\
\text { recursos ya que } \\
\text { mensualmente cada } \\
\text { ecuatoriano aporta cierto } \\
\text { porcentaje de acuerdo a } \\
\text { sueldo y otro porcentaje lo } \\
\text { asume cada patrono, esto } \\
\text { permite en un futuro poder } \\
\text { jubilarse y percibir ese dinero } \\
\text { depositado durante años, sin } \\
\text { embargo, ante la falta de } \\
\text { liquidez por parte del Estado, } \\
\text { el mismo comenzó a tomar } \\
\text { proporciones de dinero } \\
\text { prestado para hacer obras } \\
\text { públicas y entre otros. La } \\
\text { problemática radica en que el } \\
\text { préstamo interno entre ambas } \\
\text { partes, el Estado la quiere dar } \\
\text { por deuda desconocida. }\end{array}$ & $\begin{array}{l}\text { Son posibles de reprogramar, } \\
\text { existen instituciones } \\
\text { internacionales que dan este } \\
\text { servicio y pueden ofrecernos } \\
\text { un financiamiento mejor que } \\
\text { al que habíamos adquirido } \\
\text { con anterioridad, pero hay } \\
\text { algunas condiciones, sí } \\
\text { acudimos al Fondo Monetario } \\
\text { Internacional, Banco } \\
\text { Mundial, siempre estos } \\
\text { préstamos vienen con varias } \\
\text { condiciones de tipo } \\
\text { económico, los impactos } \\
\text { serían muy fuertes porque } \\
\text { nuestra economía se ha } \\
\text { manejado con un perfil hacia } \\
\text { la izquierda. }\end{array}$ & $\begin{array}{l}\text { No todo un siempre son } \\
\text { cosas buenas, no puedo hacer } \\
\text { un tratado de libre comercio } \\
\text { con Chile donde ellos me } \\
\text { van a mandar un carro, o por } \\
\text { poner; chocolate elaborado y } \\
\text { yo les mando una materia } \\
\text { prima, para nuestra } \\
\text { economía no pueden ser } \\
\text { saqueadores y que nos } \\
\text { ingresen pocos dólares. } \\
\text { Nuestra balanza comercial } \\
\text { siempre está en desventaja } \\
\text { este tipo de tratados } \\
\text { bilaterales no han sido en la } \\
\text { historia del Ecuador } \\
\text { representativos de igual a } \\
\text { igual siempre ha sido una } \\
\text { parte que nos perjudica y el } \\
\text { gobierno de Rafael Correa } \\
\text { lamentablemente tuvo que } \\
\text { decirle que no podemos } \\
\text { llevar ningún tipo de tratado }\end{array}$ \\
\hline
\end{tabular}




\begin{tabular}{|c|c|c|c|}
\hline $\begin{array}{l}\text { Sector } \\
\text { Transporte }\end{array}$ & $\begin{array}{l}\text { Todo esto pone en riesgo } \\
\text { los planes que muchos } \\
\text { ecuatorianos realizan con el } \\
\text { dinero esperado y ganado } \\
\text { de su propio esfuerzo, el } \\
\text { gobierno como tal ante } \\
\text { diversas resoluciones quiere } \\
\text { dar a conocer que esa deuda } \\
\text { no es de ese gobierno sino } \\
\text { de gobiernos anteriores para } \\
\text { no asumir la deuda en sí. } \\
\text { También estas medidas } \\
\text { pueden poner en peligro la } \\
\text { solvencia económica del } \\
\text { propio IESS por parte del } \\
\text { Estado }\end{array}$ & $\begin{array}{l}\text { El Fondo Monetario } \\
\text { Internacional siempre pide } \\
\text { medidas de autoridad fiscal, } \\
\text { reducción de burocracia e } \\
\text { incremento en tasas de } \\
\text { interés es decir, las que } \\
\text { tradicionalmente son de } \\
\text { economía de derecha, } \\
\text { entonces tendremos un } \\
\text { impacto sumamente fuerte, } \\
\text { las condiciones del país } \\
\text { cambiaran, se debe analizar } \\
\text { si vale la pena el } \\
\text { refinanciamiento. }\end{array}$ & $\begin{array}{l}\text { Son acuerdos entre estados, } \\
\text { tenemos el acuerdo } \\
\text { multipartes con la Unión } \\
\text { Europea y se ha visto el } \\
\text { impacto que ha tenido en } \\
\text { ciertos sectores de las } \\
\text { industrias podemos decirlo } \\
\text { así como productos de } \\
\text { consumo masivo, } \\
\text { productos básicos también } \\
\text { lo hemos visto en el sector } \\
\text { automotriz. Hoy en día los } \\
\text { clientes pueden acceder a } \\
\text { productos de calidad con } \\
\text { un costo más bajo. }\end{array}$ \\
\hline $\begin{array}{l}\text { Sector } \\
\text { Seguros }\end{array}$ & $\begin{array}{l}\text { Debe reformarse ciertas } \\
\text { leyes y estructurar más la } \\
\text { parte legal del IESS en } \\
\text { cuanto al poder legislativo } \\
\text { del Estado, formalizar su } \\
\text { postura organizacional y } \\
\text { dejar en claro que el IESS } \\
\text { es un seguro de todos los } \\
\text { ecuatorianos, de ellos es su } \\
\text { financiamiento, no puede } \\
\text { ser posible que se tome } \\
\text { dinero prestado y se deje } \\
\text { sin liquidez al verdadero } \\
\text { dueño. Tal vez la intención } \\
\text { del Estado al momento de } \\
\text { tomar prestado dinero de él, } \\
\text { no vio si sus posibilidades } \\
\text { estaban acordes para pagar, } \\
\text { la irresponsabilidad } \\
\text { permitió que la deuda } \\
\text { crezca. }\end{array}$ & $\begin{array}{l}\text { Pueden afectarse pagos a } \\
\text { servidores públicos en } \\
\text { temas de salud, educación, } \\
\text { esto es claramente una } \\
\text { afectación a nivel de vida } \\
\text { de la gente del pueblo } \\
\text { Ecuatoriano y nos afecta } \\
\text { porque la verdad, recursos } \\
\text { propios en el momento, en } \\
\text { el corto plazo es un poco } \\
\text { difícil de obtener para llevar } \\
\text { a este financiamiento y a } \\
\text { forma internacional } \\
\text { debemos de salir } \\
\text { completamente de un } \\
\text { modelo económico que } \\
\text { hemos venido siguiendo. }\end{array}$ & $\begin{array}{l}\text { Lo que si sería conveniente } \\
\text { es establecer bien las } \\
\text { normas y los parámetros de } \\
\text { estos acuerdos si estamos } \\
\text { teniendo unos beneficios en } \\
\text { este caso de Ecuador con la } \\
\text { Unión Europea poco hemos } \\
\text { atacado el tema del acuerdo } \\
\text { con la inclusión que es la } \\
\text { tasa de control aduanero que } \\
\text { se menciona que no es un } \\
\text { impuesto pero a la larga } \\
\text { incrementa el costo de los } \\
\text { productos de estos } \\
\text { importadores lo que quita } \\
\text { competitividad a estas } \\
\text { empresas en poder seguir } \\
\text { mejorando como industrias. }\end{array}$ \\
\hline $\begin{array}{l}\text { Sector de } \\
\text { la } \\
\text { Producción }\end{array}$ & $\begin{array}{l}\text { Esta deuda se ha venido } \\
\text { acarreando a través de } \\
\text { varios gobiernos, el IESS se } \\
\text { ha convertido en una caja } \\
\text { chica para el gobierno de } \\
\text { turno, entonces al tomar } \\
\text { este dinero de una manera } \\
\text { arbitraria, ya que este dinero } \\
\text { no pertenece realmente al } \\
\text { estado sino a los afiliados, } \\
\text { se ha ido incrementando lo } \\
\text { que es la deuda a través de } \\
\text { estos años no sólo en el } \\
\text { período de Rafael Correa } \\
\text { como tal, sino en los } \\
\text { gobiernos precedentes, esta }\end{array}$ & $\begin{array}{l}\text { Es ideal refinanciar, pero es } \\
\text { una utopía, muchas de las } \\
\text { mejores economías del } \\
\text { mundo no son cerradas en } \\
\text { mantener gasto público, las } \\
\text { mejores economías del } \\
\text { mundo tienen una fuerte de } \\
\text { participación del estado en } \\
\text { deuda razonable. Se habla a } \\
\text { veces de eliminar la } \\
\text { burocracia, pero siempre } \\
\text { teniendo en cuenta de no } \\
\text { dejar desatendidas aéreas } \\
\text { muy importantes. }\end{array}$ & $\begin{array}{l}\text { La clave fundamental que } \\
\text { utilizaría el gobierno es una } \\
\text { menor cantidad de } \\
\text { impuestos a las empresas y } \\
\text { así poder invertir capital en } \\
\text { el país haciendo que se } \\
\text { reactive la economía, } \\
\text { mientras mayor sea la } \\
\text { inversión y muchas } \\
\text { empresas se agreguen a esta } \\
\text { nueva revolución, el país se } \\
\text { podrá mantener } \\
\text { económicamente así } \\
\text { generará una mayor } \\
\text { cantidad de empleo } \\
\text { haciendo más estable la }\end{array}$ \\
\hline
\end{tabular}




\begin{tabular}{|c|c|c|c|}
\hline & $\begin{array}{l}\text { deuda ha ido } \\
\text { incrementando. }\end{array}$ & & $\begin{array}{l}\text { economía y que se } \\
\text { mantenga a un largo plazo. }\end{array}$ \\
\hline $\begin{array}{l}\text { Sector } \\
\text { Bancario }\end{array}$ & $\begin{array}{l}\text { El Estado aduce que el } \\
\text { dinero que se encuentra en } \\
\text { el IESS no es de los } \\
\text { afiliados, algo que no es } \\
\text { 100\% verdad, porque éste } \\
\text { es un dinero que aportan } \\
\text { todos los trabajadores, } \\
\text { aportamos mes a mes, } \\
\text { entonces lo que ellos } \\
\text { aducen que es un dinero } \\
\text { que se encuentra ahí } \\
\text { reposando y que no genera } \\
\text { un retorno no genera una } \\
\text { utilidad y dicen que pueden } \\
\text { darle un mejor manejo para } \\
\text { mantener una estabilidad } \\
\text { micro y macro- económica } \\
\text { ya que este dinero es como } \\
\text { que un colchón. Para ellos } \\
\text { es un soporte; en algún } \\
\text { momento los afiliados y los } \\
\text { jubilados reclaman estos } \\
\text { fondos y al extraerlo les } \\
\text { estamos dejando sin ese } \\
\text { beneficio a nuestros } \\
\text { jubilados. Entonces el } \\
\text { tomar como Caja Chica nos } \\
\text { muestra que hay un mal } \\
\text { manejo de la gestión } \\
\text { económica en el gobierno y } \\
\text { no sólo en este, sino en } \\
\text { todos qué le anteceden. }\end{array}$ & $\begin{array}{l}\text { No hay en ocasiones } \\
\text { suficiente liquidez para } \\
\text { cumplir con las deudas que } \\
\text { tenemos, proveedores del } \\
\text { estado y de los municipios } \\
\text { quedan impagos, los } \\
\text { servicios empiezan a bajar } \\
\text { en tema de calidad y } \\
\text { cantidad, pueden cerrarse } \\
\text { dispensarios médicos, } \\
\text { hospitales, o sea afecta } \\
\text { muchísimo a la República, } \\
\text { todo esto lleva a que la } \\
\text { calidad de vida del pueblo } \\
\text { empiece a descender y se } \\
\text { vea muy golpeada al no } \\
\text { tener suficiente liquidez } \\
\text { para cumplir con las } \\
\text { obligaciones que el estado } \\
\text { tiene. Podemos tratar de } \\
\text { reducir un gasto } \\
\text { administrativo innecesario, } \\
\text { pero no yéndonos en contra } \\
\text { de la salud, seguridad } \\
\text { pública, educación u otros } \\
\text { factores que son parte } \\
\text { importante en la vida de la } \\
\text { gente. }\end{array}$ & $\begin{array}{l}\text { Esta inversión extranjera } \\
\text { aumenta la disponibilidad } \\
\text { de tecnología adecuada } \\
\text { para el proceso de } \\
\text { producción, importada de } \\
\text { países con un mayor grado } \\
\text { de desarrollo y adaptadas a } \\
\text { las condiciones locales. } \\
\text { Esto se complementa con } \\
\text { un incremento de la } \\
\text { competencia de empresas } \\
\text { extranjeras que también } \\
\text { quieren invertir en el país. } \\
\text { Es así que los nuevos } \\
\text { tratados beneficiaran a las } \\
\text { empresas generando más } \\
\text { ingresos directamente al } \\
\text { país, eso hace que las } \\
\text { empresas incremente sus } \\
\text { bolsas de valores y poder } \\
\text { generar una mayor cantidad } \\
\text { de empleo, ya que es lo } \\
\text { fundamental que se necesita } \\
\text { en la actualidad con la } \\
\text { economía ecuatoriana que } \\
\text { se está viviendo el } \\
\text { desarrollo económico debe } \\
\text { incrementar con estos } \\
\text { tratados que se van a } \\
\text { realizar. }\end{array}$ \\
\hline $\begin{array}{l}\text { Sector } \\
\text { Ganadero }\end{array}$ & $\begin{array}{l}\text { Días atrás la fiscalía indicó } \\
\text { que se debe ingresar en lo } \\
\text { que era las partidas de pago } \\
\text { de deuda del estado, mostrar } \\
\text { las cifras reales, determinar } \\
\text { el verdadero riesgo país, ya } \\
\text { que el país se encuentra } \\
\text { afectado, fue castigado ya } \\
\text { que se estaba vulnerando el } \\
\text { derecho de los jubilados y de } \\
\text { los afiliados que están en el } \\
\text { IESS, mostrar el recorte de } \\
\text { plan de inversión. }\end{array}$ & $\begin{array}{l}\text { Sin lugar a dudas tener una } \\
\text { economía que está demasiado } \\
\text { endeudada y que de pronto no } \\
\text { tiene mecanismos regulados } \\
\text { para saber hasta qué punto } \\
\text { podemos seguir } \\
\text { financiándonos con deuda, } \\
\text { damos una impresión que no } \\
\text { generamos divisas o la } \\
\text { suficiente fuerza económica } \\
\text { para poder solventar nuestros } \\
\text { gastos. }\end{array}$ & $\begin{array}{l}\text { Estos actores económicos } \\
\text { que están afectando de cierta } \\
\text { manera al país son de ver de } \\
\text { qué manera nosotros } \\
\text { podemos sacar ventaja } \\
\text { administrando los recursos, } \\
\text { al beneficio económico, } \\
\text { entre otros. Podemos ver que } \\
\text { ciertos temas que se ha } \\
\text { tratado, la mayoría se enfoca } \\
\text { a lo monetario y no estamos } \\
\text { velando de cierta manera por } \\
\text { una solución óptima de } \\
\text { integración entre naciones. }\end{array}$ \\
\hline
\end{tabular}

Fuente: Elaboración Propia

Tabla 3. Crecimiento de la Economía, Petróleo y Reactivación Económica

\begin{tabular}{llll}
\hline Experto & Crecimiento de la Economía Petróleo Reactivación Económica
\end{tabular}




\begin{tabular}{|c|c|c|c|}
\hline $\begin{array}{l}\text { Sector } \\
\text { Hotelero }\end{array}$ & $\begin{array}{l}\text { El país lamentablemente no } \\
\text { tiene liquidez por los errores } \\
\text { políticos, aquí todo es } \\
\text { corrupción y todo es planeado } \\
\text { entonces quien va a venir a } \\
\text { invertir, lo que estamos } \\
\text { haciendo es buscar medidas } \\
\text { que permitan conllevar a la } \\
\text { mejora de nuestra situación, se } \\
\text { quiere satanizar una deuda por } \\
\text { el cual tenemos que analizar } \\
\text { donde están las fallas que se } \\
\text { quieran corregir. }\end{array}$ & $\begin{array}{l}\text { No es un endeudamiento de } \\
\text { dólares sino en recursos } \\
\text { pues no da una rigidez muy } \\
\text { dura porque de pronto no } \\
\text { podemos hacer utilización } \\
\text { de contratos en el futuro con } \\
\text { mejores precios o venderlo a } \\
\text { una mejor posición si es que } \\
\text { el petróleo llegase a subir. }\end{array}$ & $\begin{array}{l}\text { Es un intento de mejorar la } \\
\text { parte productiva, sin embargo } \\
\text { hay unos temas que no los } \\
\text { comparten los empresarios } \\
\text { que se puede decir sean los } \\
\text { de mayor participación en } \\
\text { valores en facturación. Hay } \\
\text { temas que tienen tinte } \\
\text { político y no son } \\
\text { convenientes, no tiene } \\
\text { sentido ni es procedente } \\
\text { porque es más una carga } \\
\text { política impositiva que } \\
\text { productiva y de reactivación. }\end{array}$ \\
\hline $\begin{array}{l}\text { Sector } \\
\text { Transporte }\end{array}$ & $\begin{array}{l}\text { Existe un grupo de economistas } \\
\text { que no tienen nada de notable, } \\
\text { todos han sido parte de la } \\
\text { partidocracia que ha } \\
\text { perjudicado a este país, no han } \\
\text { hecho nada, han facturado } \\
\text { aumentando exageradamente } \\
\text { precio de contratación en } \\
\text { inversiones como son las } \\
\text { carreteras, hospitales y las } \\
\text { obras eléctricas inconclusas. }\end{array}$ & $\begin{array}{l}\text { El precio actual está } \\
\text { subiendo y no ha llegado a } \\
\text { niveles en precio de la época } \\
\text { de las antiguas y de pronto } \\
\text { no tener esta capacidad de } \\
\text { venderlos porque ya } \\
\text { tenemos un precio de venta } \\
\text { fijo y que no podemos tener } \\
\text { una variación para tener una } \\
\text { mayor utilidad y si nos frena } \\
\text { las posibilidades de tener } \\
\text { más recursos. }\end{array}$ & $\begin{array}{l}\text { Se debe buscar la manera en } \\
\text { que podamos velar por leves } \\
\text { que administren el país en } \\
\text { cuanto a recursos y beneficio } \\
\text { económico. Ciertos temas se } \\
\text { han tratado, la mayoría se } \\
\text { enfocan a lo monetario } \\
\text { incluso a la pérdida y la } \\
\text { cooperación de como la } \\
\text { deuda externa está creciendo } \\
\text { y no estamos velando de } \\
\text { cierta manera por una } \\
\text { solución óptima de cómo } \\
\text { disminuirla. }\end{array}$ \\
\hline $\begin{array}{l}\text { Sector } \\
\text { Seguros }\end{array}$ & $\begin{array}{l}\text { Todos tenemos que } \\
\text { endeudarnos, si queremos } \\
\text { comprar una casa tenemos que } \\
\text { endeudarnos, tener una deuda } \\
\text { en nuestra economía no es } \\
\text { malo, debemos previamente } \\
\text { revisar los tipos de convenios o } \\
\text { la tasa de interés que nos } \\
\text { cobran o el petróleo que se } \\
\text { entrega. No existe incremento } \\
\text { en las construcciones porque } \\
\text { también va relacionado con la } \\
\text { bajada del tema relacionado a } \\
\text { la plusvalía. }\end{array}$ & $\begin{array}{l}\text { La etapa en la cual teníamos } \\
\text { bonanza petrolera que } \\
\text { permitía solventar los gatos, } \\
\text { se terminó. Ahora con un } \\
\text { petróleo bajo y se ha cerrado } \\
\text { esta llave de para seguir } \\
\text { gastando en un mismo nivel } \\
\text { y ya no tenemos el dinero } \\
\text { para hacerlo. Entonces } \\
\text { pedimos prestado a la OMC } \\
\text { al costo que ea con tal de } \\
\text { continuar esta supuesta } \\
\text { bonanza }\end{array}$ & $\begin{array}{l}\text { De pronto hemos tenido una } \\
\text { ansiedad o una desesperanza } \\
\text { de poder pagar un nivel de } \\
\text { gastos tan alto en la deuda } \\
\text { pública para generar los } \\
\text { demás. En cuanto a esa } \\
\text { imagen, el gobierno trata de } \\
\text { hacer todo lo que más pueda } \\
\text { por el público, pero a base de } \\
\text { un dinero que tiene un costo } \\
\text { muy alto y es muy riesgoso } \\
\text { que se mitiga y se siga } \\
\text { inflando este nivel de deuda. }\end{array}$ \\
\hline $\begin{array}{l}\text { Sector de } \\
\text { la } \\
\text { producción }\end{array}$ & $\begin{array}{l}\text { Nuestro país es bastante } \\
\text { turístico; si nosotros cogemos y } \\
\text { reinvertimos el Impuesto a la } \\
\text { renta en el sector turístico } \\
\text { puede ser favorable, dándole } \\
\text { crecimiento al país ya que } \\
\text { atraemos a turistas significando } \\
\text { ingreso de efectivo, también si } \\
\text { no se obra la salida de divisas } \\
\text { por importaciones se puede } \\
\text { mejorar la economía del país. }\end{array}$ & $\begin{array}{l}\text { Al haber paro en la refinería } \\
\text { existirá un problema para } \\
\text { cumplir con la demanda de } \\
\text { los contratos que tenemos ya } \\
\text { firmados con lo que es } \\
\text { China y Tailandia, sabemos } \\
\text { que tenemos una preventa } \\
\text { establecida en ciertos } \\
\text { períodos, el cual tenemos } \\
\text { que cumplir a cabalidad. }\end{array}$ & $\begin{array}{l}\text { ¿Qué dinero extranjero va a } \\
\text { venir al Ecuador? } \\
\text { Debido a las constantes } \\
\text { críticas y a la falta de } \\
\text { acciones se crea una política } \\
\text { inestable, entonces no habría } \\
\text { dinero en el mundo de } \\
\text { ningún inversionista para } \\
\text { querer invertir con toda la } \\
\text { corrupción descubierta y con } \\
\text { la falta de compromiso de } \\
\text { nuestros dirigentes. }\end{array}$ \\
\hline $\begin{array}{l}\text { Sector } \\
\text { Bancario }\end{array}$ & $\begin{array}{l}\text { Si no estamos cobrando el } \\
\text { impuesto a las exportaciones }\end{array}$ & $\begin{array}{l}\text { El Ecuador no será capaz de } \\
\text { cubrir con esta demanda de }\end{array}$ & $\begin{array}{l}\text { En el gobierno anterior, } \\
\text { muchas veces parecía que }\end{array}$ \\
\hline
\end{tabular}




\begin{tabular}{|c|c|c|c|}
\hline & $\begin{array}{l}\text { otras empresas pueden tener la } \\
\text { facilidad de importar las } \\
\text { maquinarias productos que } \\
\text { necesiten para la producción } \\
\text { total del producto final y el } \\
\text { mismo sea comercializado aquí } \\
\text { en Ecuador o ya sea exportado } \\
\text { a diferentes países, este factor } \\
\text { permite dar valor agregado a } \\
\text { nuestros productos. Al importar } \\
\text { en maquinarias, el costo de } \\
\text { producción del producto sería } \\
\text { mucho menor, de esta manera } \\
\text { crece el país. }\end{array}$ & $\begin{array}{l}\text { Petróleo por lo menos hasta } \\
\text { que se regularice y hasta que } \\
\text { se pueda sanear los } \\
\text { problemas que tiene. Existe } \\
\text { una polémica debido a que } \\
\text { se supone que esto debería } \\
\text { de estar en marcha y debería } \\
\text { de estar produciendo en una } \\
\text { manera continua, nosotros } \\
\text { vamos a tener que importar } \\
\text { insumos para poder cubrir } \\
\text { con el día a día de los } \\
\text { ecuatorianos ya sea esto en } \\
\text { combustibles o en otros } \\
\text { derivados. }\end{array}$ & $\begin{array}{l}\text { podía ser hasta un pecado } \\
\text { crecer como grupo, como } \\
\text { empresa y los empresarios se } \\
\text { sentían muy incómodos por } \\
\text { muchas cosas, sin embargo, } \\
\text { hubo muchas condiciones } \\
\text { para salir y seguir adelante, el } \\
\text { gobierno actual está } \\
\text { empreñado en poder } \\
\text { recuperarse, primero debe } \\
\text { cubrir todo el endeudamiento } \\
\text { que nos dejó el gobierno } \\
\text { actual está empeñado en } \\
\text { poder recuperarse, primero } \\
\text { debe cubrir todo el } \\
\text { endeudamiento que nos dejó } \\
\text { el gobierno anterior y } \\
\text { segundo, permitir que haya } \\
\text { más productividad más } \\
\text { producción, más trabajo. }\end{array}$ \\
\hline $\begin{array}{l}\text { Sector } \\
\text { Ganadero }\end{array}$ & $\begin{array}{l}\text { Si se logra lanzar un proyecto } \\
\text { beneficioso en el ámbito } \\
\text { económico con mucha } \\
\text { acogida tenemos que pensar } \\
\text { que el beneficio no está en el } \\
\text { aumento o reducción del } \\
\text { circulante, sino más bien en la } \\
\text { seguridad y rapidez que } \\
\text { puedan inyectar esto al } \\
\text { sistema y a todo el ambiente } \\
\text { macroeconómico del país. }\end{array}$ & $\begin{array}{l}\text { Se debería auditar si } \\
\text { realmente ese dinero fue } \\
\text { invertido en lo que es } \\
\text { mejoras para la refinería } \\
\text { porque por lo que se ha } \\
\text { podido ver es que este } \\
\text { dinero ha sido mal } \\
\text { utilizado, en estos } \\
\text { momentos se vive el hecho } \\
\text { de que cada día se revelan } \\
\text { pruebas contundentes de } \\
\text { desviación de fondos. }\end{array}$ & $\begin{array}{l}\text { Los temas económicos del } \\
2018 \text { no son fáciles, nuestra } \\
\text { balanza comercial es } \\
\text { negativa perdemos dólares } \\
\text { en cada importación, nos } \\
\text { ingresa poco dinero de la } \\
\text { inversión extranjera, cada } \\
\text { vez las deudas } \\
\text { internacionales aumentan, se } \\
\text { necesita tomar decisiones } \\
\text { para reestablecer al país. }\end{array}$ \\
\hline
\end{tabular}

Fuente: Elaboración Propia

\section{Discusión}

Se han visto tantos intentos a lo largo de la historia con diferentes gobiernos con respecto al agro, reformas agrarias, pero la verdad es que el Ecuador antes de ser petrolero era un país agrícola. Si, ¿y qué sucede? Nos quedamos dependiendo del petróleo, nuestra abundancia fue por el precio del petróleo, sin embargo, Ecuador tiene cultivos hasta cuatro veces al año en determinados productos. La cuenca del Guayas es una tierra realmente bendita donde uno tira un papel, y le sale una planta de papel, así de fértil, entonces ahí podríamos ser en realidad el granero de América, se debe incentivar la producción de cara hacia fuera, nuestro mercado es pequeño, Ecuador es un país con 17 millones de habitantes, si sumamos los que están en España, en Italia, en Estados Unidos, en otras palabras es un mercado muy limitado y se tiene que pensar hacia fuera para buscar exportar la mayor cantidad de productos, ¿qué puede ser algo que sea explotable?, fuimos muchísimos años exportadores de banano. La parte agroindustrial, el contrato con gente de primer nivel donde hicieron inventos tecnológicos y desarrollos moleculares inclusive para las frutas, los teleféricos, las estaciones de empaque de lavado son desarrollos con creatividad nacional ecuatoriana que fue de exportación mundial, Ecuador era 
rey indiscutible del banano en exportación por muchos años pero sigue teniendo una fruta de altísima calidad.

Actualmente el dinero electrónico es un medio que se utilizan en varios países. Realmente en Ecuador aún no se tiene clara la idea de lo que es ya que actualmente lo está manejando el Banco Central mediante sus cuentas bancarias del celular, así mismo se hacen operaciones por tarjeta de débito y crédito, así como en criptomonedas. Ecuador debe tener una idea clara de hacia dónde va el dinero electrónico porque no existen todavía garantías y es por eso que los ecuatorianos aún no se sienten seguros de optar por este medio de pago verdad, por eso muchos locales no aceptan este medio de pago todavía.

Como conocemos existen personas que se lucran de la plusvalía, se dedican a la compra y venta de viviendas para lucrarse, buscan comprar casas usadas por el precio, no todas las personas tienen los fondos para adquirir una vivienda nueva. La plusvalía ha decrecido la fuerza laboral en donde no se ven nuevas construcciones, no hay una alta demanda de obras. Es bastante claro que apuntamos a una situación que no es fácil, que ha sido muy distinto a lo que hemos venido viviendo durante 7 o 8 años cuando nuestro mayor respaldo que era el petróleo estaba a un precio internacional positivo y que permitía tener recursos necesarios para toda la república. Actualmente esta situación ha cambiado y si bien es cierto estamos en una situación difícil que se ve y se siente el impacto en toda la población en general.

Como es de conocimiento público el Ecuador tenía ciertos impuestos que le generaban alta recaudación sobre todo con el tema de aduanas, existían clientes que entregaban como impuestos al gobierno liquidaciones de $\$ 10,000$ o $\$ 12,000$; hoy en día se ven reducidas a liquidaciones de $\$ 200$ o $\$ 300$ lo que genera que el Estado reciba menos dinero y al existir el mismo gasto público alto se ve esa descompensación. El Ecuador no ha encontrado un sistema óptimo de recaudación sin verse afectado ¿por qué? porque no se ha promovido no solo a ser un estado recaudador sino que se debe promover la inversión extranjera.

\section{Conclusiones}

Para hablar sobre reactivación económica se deben conocer el manejo y antecedentes de tributos, planes de inversión, componentes del presupuesto general del estado, reformas tributarias y manejo de la deuda tanto interna como externa.

El panel de expertos manifiesta que los microempresarios que son los verdaderos consumidores finales son los más afectados debido a que estas medidas generan en algunos puntos incremento de impuestos, ese dinero exactamente ahuyenta inversión, ese pago extra hace sentir de alguna forma que en vez de premiar por tener un crecimiento se debe castigar a las empresas.

Reactivar el país es muy difícil, no basta exonerar el impuesto a la renta; de que sirve exonerarlo si existen otros organismos que causan problemas para trabajar.

\section{Bibliografía}


Ab. Jimmy Salazar Gaspar, p. d. (07 de 05 de 2015). El telégrafo. Obtenido de https://www.eltelegrafo.com.ec/noticias/judicial/12/amnistia-tributaria

Azanza Panta, L. A. (2014). Análisis del índice de rendimiento académico obtenido a través del uso del Sistema Multimedia "UNO" como metodología de enseñanza - aprendizaje en la asignatura Lenguage y Comunicación en el IPAC, en el período académico 2012 - 2013. Obtenido de http://repositorio.ucsg.edu.ec/handle/3317/2960

BCE. (01 de 03 de 2001). la dolarización en el Ecuador, un año después. la dolarización en el Ecuador, Obtenido de https://contenido.bce.fin.ec/documentos/PublicacionesNotas/Notas/Dolarizacion/pdf/ Cabezas\%20et\%20al.pdf

Comercio, D. E. (04 de 01 de 2018). Brecha fiscal creció 43\% en el 2017 y se cubrió con deuda. Obtenido de :http://www.elcomercio.com/actualidad/brecha-fiscal-deuda- gasto economia.html.

Ecuador, A. N. (28 de 12 de 2017). Registro Oficial.

Ecuador, R. N. (01 de 02 de 2018). Redcedia. Obtenido de https://www.cedia.edu.ec/es/servicios def/innovar/actores/sector-productivo-del-pais

Morales. (01 de 31 de 2011). Repositorio Digital-UPS. Obtenido de Análisis de la legalidad del anticipo al Impuesto a la Renta para sociedades, sucesiones indivisas y personas naturales obligadas a llevar contabilidad: http://dspace.ups.edu.ec/handle/123456789/3081

Morales Figueroa, F. R. (28 de 08 de 2015). Repositorio Universidad de Guayaquil . Obtenido de http://repositorio.ug.edu.ec/handle/redug/9259

Ocles. (02 de 02 de 2017). Repositorio UASB. Obtenido de Las industrias del sector poliestireno en el marco del Código Orgánico: http://repositorio.uasb.edu.ec/bitstream/10644/6032/1/T2524-MT-Ocles Las\%20industrias.pdf

Plaehn, T. (2018). ¿Por qúe comprar bonos del Tesoro de Estados Unidos? Cuida tu dinero, 1. república, L. (13 de 08 de 2018). La República. Obtenido de https://www.larepublica.ec/blog/economia/2018/08/13/deficit-fiscal-en-ecuador-bajo- 1 500-millones-dolares-en-primeros-7-meses-ano/

SRI. (09 de 12 de 2017). SRI. Obtenido de http://www.sri.gob.ec/web/guest/ley-organica- para-la reactivacion-de-la-economia-y-fortalecimiento

Universo, E. (09 de 06 de 2019). El Universo. Obtenido de La salida para el Gobierno de Lenín Moreno en su afán de que haya equilibrio fiscal y menor endeudamiento tiene varias aristas: reducir el tamaño del Estado, optimizar el presupuesto, la Ley de Fomento Productivo que incluye remisión tributaria para logra 
Vega Morales, P. (11 de 11 de 2007). El panel de expertos.El programa de monitoreo de la política social.Dos experiencias de evaluación de. Obtenido de http://www.redalyc.org/pdf/195/19500808.pdf

Vera, \& Carpio. (31 de 01 de 2011). Repositorio Digital UPS. Obtenido de Análisis del impacto de los incentivos tributarios establecidos en el Código de la Producción para el año 2011, en el sector de la Pequeña Industria del Azuay: https://dspace.ups.edu.ec/handle/123456789/3083 